\title{
Home Range and Habitat Disturbance Identification for a Vulnerable Shorebird Species (Larus saundersi) in the Yellow River Delta, China
}

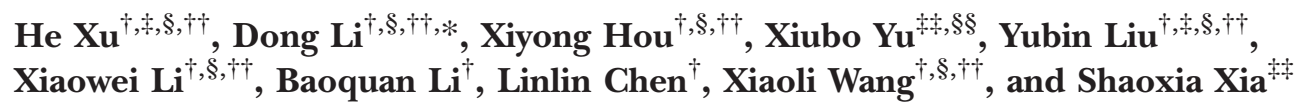

${ }^{\dagger}$ Yantai Institute of Coastal Zone Research

Chinese Academy of Sciences

Yantai, Shandong 264003, P.R. China

${ }^{\S}$ CAS Key Laboratory of Coastal Environmental Processes and Ecological Remediation

Yantai Institute of Coastal Zone Research

Chinese Academy of Sciences

Yantai, Shandong 264003, P.R. China

\# Key Laboratory of Ecosystem Network Observation and Modeling Institute of Geographic Sciences and Natural Resources Research Chinese Academy of Sciences Beijing 100101, P.R. China
*University of Chinese Academy of Sciences Beijing 100049, P.R. China

${ }^{\dagger}$ Center for Ocean Mega-Science

Chinese Academy of Sciences

Qingdao, Shandong 266071, P.R. China

${ }^{\S}$ College of Resources and Environment University of Chinese Academy of Sciences Beijing 100049, P.R. China

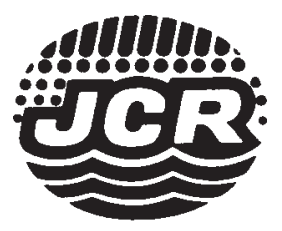

www.JCRonline.org

ABSTRACT

Xu, H.; Li, D.; Hou, X.; Yu, X.; Liu, Y.; Li, X.; Li, B.; Chen, L.; Wang, X., and Xia, S., 0000. Home range and habitat disturbance identification for a vulnerable shorebird species (Larus saundersi) in the Yellow River Delta, China. Journal of Coastal Research, 00(0), 000-000. Coconut Creek (Florida), ISSN 0749-0208.

Understanding the home range of animal species can be helpful to biodiversity and habitat conservation. Saunders's Gull (Larus saundersi), one of the vulnerable birds in the world, has become an important indicator species to measure the quality of ecological environment in the coastal wetlands of the Yellow River Delta. Information about habitat selection of the species has so far been mainly from field survey. In view of the successful application of satellite tracking in animal ecology, two individual birds were tagged for home range identification and habitat disturbance analysis. The gull's home range was confirmed using the Brownian bridge movement model. Habitat disturbances information from anthropogenic activities was analyzed by kernel density estimation as well as buffer zone analysis. Considering the gregariousness of the shorebird, the tracking sample data, though limited, can reflect the species' habitat selection to a certain extent. The results showed that (1) the Saunders's Gull's main home range was located in the northern and eastern coastal areas of Dongying city, the seashore area at the border of Binzhou with Dongying and Cangzhou city, and the Nanpu wetland of Tangshan city; and (2) human activity had a substantial effect on the home range selection, for example, mariculture was an important part of its home range, the Saunders's Gull exhibited an approach-avoidance behavior to wind turbines and oil wells, and activity time varied with different distances to the road. The study provides insights into the behavior of the shorebird and is of great significance to sustainable development of the human-environment relationship in the Yellow River Delta.

ADDITIONAL INDEX WORDS: Saunders's Gull, satellite tracking, Brownian bridge movement model, human activity, remote sensing, geographic information system.

\section{INTRODUCTION}

The way wildlife uses space has attracted the interest of numerous ecological and behavioral researchers (Franzreb, 2006; Mohr, 1947; Seifert, Tegetmeyer, and Ornes, 2018). Most studies pay attention to why the animal is at a particular place at a particular time and the concept of home range is usually focused on in these research fields. Home range is defined as "that area traversed by the individual in its normal activities of food gathering, mating and caring for young" (Burt, 1943). Some methods of home range analysis have been developed,

DOI: 10.2112/JCOASTRES-D-20-00091.1 received 6 July 2020; accepted in revision 21 November 2020; corrected proofs received 19 January 2021; published pre-print online 4 February 2021.

*Corresponding author: dli@yic.ac.cn

${ }^{\circ}$ Coastal Education and Research Foundation, Inc. 2021 including minimum convex polygons (MCPs) (Mohr, 1947), grid cells (Siniff and Tester, 1965), probabilistic methods (Van Winkle, 1975), harmonic mean method (Dixon and Chapman, 1980), two-dimensional cluster analysis (Hirons, 1988), kernel methods (Van Winkle, 1975), and the Brownian bridge movement model (BBMM) (Horne et al., 2007). Studies have shown that though each method can determine the size and shape of the home range, no one is "perfect." For example, relatively minor changes to the smoothing parameters may have a great effect on overall range size when using probabilistic methods (Harris et al., 1990). Similarly, home range estimation based on MCPs also ignores the actual movement between different locations (Buchin et al., 2015). GPS tracking, having obvious advantages over traditional manual observation and radio tracking in terms of survey scope 
and data accuracy, is used to provide precise information about location and movement of a species (Naď et al., 2019). Home range size and patterns of space utilization can be determined using analytical methods based on the GPS tracking data. In recent years, the GPS tracking technique has been applied to studies of different types of animals, such as Audouin's gull (Larus audouinii) (Christel et al., 2012), Pied avocets (Recurvirostra avosetta) (Enners et al., 2019), Mongolian gazelles (Procapra gutturosa) (Ito et al., 2018), giant noctule (Nyctalus lasiopterus) (Nado et al., 2019), and Australian Wood Ducks (Chenonetta jubata) (McEvoy, Hal, and McDonald, 2019) to explore the relationship between species and environment. Considering its importance in the field of animal ecology, Coxen et al. (2017) indicated that satellite transmitters may be the only tool available to effectively track fine-scale movements of highly mobile, difficult-to-access species.

Saunders's Gull (Larus saundersi) was recognized as "vulnerable" by the International Union for Conservation of Nature (IUCN) and BirdLife International in 2008 (Jiang et al., 2010). Based on analysis of records and surveys by BirdLife International (2018), the mature shorebird population estimate is 14,400 . The threatened species breeds at several localities on the coastal area of eastern China and the west coast of South Korea (Yoon et al., 2013) and spends the nonbreeding period along the coastlines of China, Vietnam, the west and south Korean Peninsula, and SW Japan (Cao, Barter, and Wang, 2008). It is restricted to Common Seepweed (Suaeda glauca) habitats, many of which have been lost and degraded because of human disturbance, resulting in a decrease in the species' population (Jiang et al., 2010). The Yellow River Delta (YRD), a representative and ecologically important shorebird stopover site in the middle of the East Asian-Australasian Flyway (Cao, Barter, and Wang, 2008; Li et al., 2019), is one of three major breeding areas for the Saunders's Gull in China (Bai et al., 2015). It is known that coastal wetlands act as an interface between aquatic and terrestrial ecosystems, playing a key role in the promotion of plant and animal diversity and abundance over the entire landscape (Gibbes, Southworth, and Keys, 2009; Mao et al., 2014; Munroe, Croissant, and York, 2005; Sui et al., 2015). With large-scale tidal flat wetlands, intertidal zone, and estuaries (Liu et al., 2019; Lyu et al., 2015; Yao et al., 2016), the YRD provides an ideal natural place for the Saunders's Gull to breed, inhabit, and forage. There is abundant Common Seepweed, crabs, small fish, shellfish in salt marshes, and tidal mudflats, on which the shorebird's specialized diet depends (Mallon and Jiang, 2009). However, in recent decades, the wetland ecosystems of the YRD have undergone remarkable changes as a result of frequent low-flow conditions of the Yellow River and increases in energy exploration, road construction, and beach reclamation (Bi, Wang, and $\mathrm{Lu}, 2011$; Cao et al., 2015). Previous studies have shown that human disturbances, such as habitat fragmentation from anthropogenic structures and traffic, have greater influence than natural environmental variables on the distribution of wildlife (Batsaikhan et al., 2014; Ito et al., 2018; Mallon and Jiang, 2009). In view of the representativeness of Saunders's Gull in bird biodiversity conservation of the YRD, it is important to understand its habitat status for coastal wetlands ecosystems protection.
Information about habitat selection and use by Saunders's Gull as well as other shorebirds in the YRD area has so far been derived mainly from manual field survey work, whereas satellite tracking techniques have been successfully used for studying other wildlife in many other areas. Thus, the goal of the current paper is to (1) identify the home range of several Saunders's Gull individuals based on satellite tracking data, and (2) explore the relationship between human activity and Saunders's Gull habitat selection in the YRD area based on high-resolution satellite images. As far as is known, it is the first time Saunders's Gull movement was tracked using satellite transmitters in the YRD region. Although the samples obtained are limited, the data obtained as well as the corresponding analysis are still of great value for providing insights into the behavior of shorebirds, which may have important implications for understanding shorebird ecology and conservation.

\section{METHODS}

The research was conducted in strict accordance with animal care permits issued by China's State Forestry Administration. The field surveys and bird hunting were authorized by the Department of Natural Resources of Shandong Province and Management Bureau of the Yellow River Delta Nature Reserve of China. The number of the permit is Shandong Hunting License No. 001 (2018).

\section{Study Area}

The YRD, mainly in the city of Dongying, is located on the SW coast of the Bohai Sea, eastern China (Figure 1). A large amount of silt flowed into Bohai Sea via the Yellow River because of serious soil erosion in the Loess Plateau and created the continuous, fast-growing natural delta at the river mouth (Bi, Wang, and Lu, 2011). Benefiting from its natural largescale tidal wetlands and flat intertidal zone, the YRD is known for its rich biodiversity supported by various habitats and has become an important overwintering stopover and breeding site for migrating birds. This site used to support more than 70,000 shorebirds during southward migration and an estimated more than 100,000 during northward migration (Li et al., 2019). Due to the outstanding contributions in protecting Saunders's Gull in the YRD, Dongying was awarded the title of the home of Saunders's Gull in 2016. However, human activities, such as petroleum exploration, wind power generation, land reclamation, etc., in the coastal area have inevitably disturbed the habitat of the shorebird. There are more than 3500 oil wells and 350 wind turbines in the intertidal zone of the YRD alone. Information about human-shorebird conflicts is urgently needed for ecological protection. Considering land-use data availability and the moving route of the shorebird, the $15-\mathrm{km}$ buffer zone of the Saunders's Gull's migration path was chosen in the YRD coastal zone (YRDCZ) as the study area.

\section{Satellite Tracking of Birds}

In this research, two adult Saunders's Gulls were trapped by mist net near their breeding sites (Yiqianer station) and foraging estuary (Dawenliu station) in the YRD in May 2018, and a backpack satellite tag (HQBG1107) was deployed on each bird (Figure 2). The solar-powered satellite tags, with battery lives of more than 5 years, were made by Hunan Global 

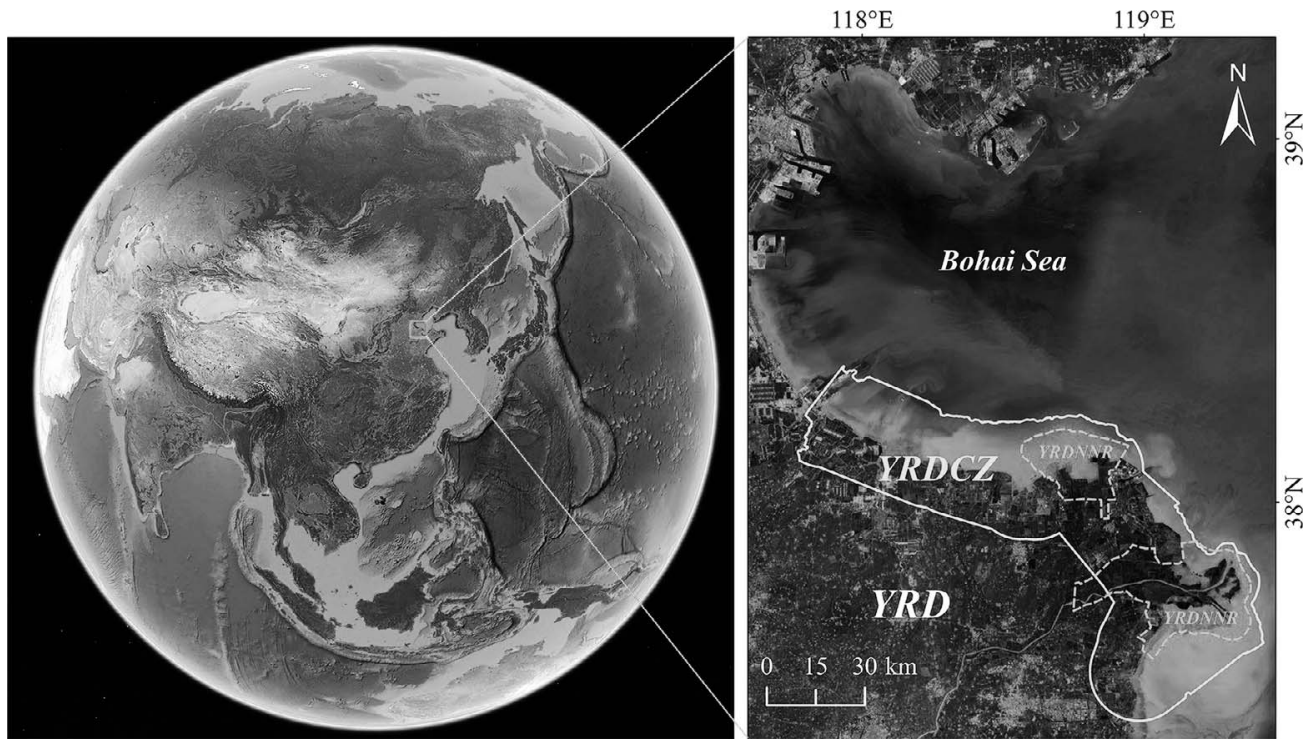

Figure 1. Location of the Yellow River Delta (YRD), eastern China. The solid outline is the extent of the study area, obtained by buffering the seabird migration trajectory (15-km buffer zone) in the YRD coastal zone (YRDCZ). The dotted line indicates the boundary of the YRD National Nature Reserve (YRDNNR). The abbreviations marked in the following figures are the same as Figure 1.

Messenger Technology Co., Ltd. The satellite tracker was inspected and approved by Hunan Testing Institute of Product and Commodity Supervision. The combined weight of the harness and tag is $7 \mathrm{~g}$, less than $3 \%$ of the bird's body weight. If the tracker weight is within the required range and it is installed correctly, it will not affect the normal activities of the bird (Burnside et al., 2019; O'Mara, Wikelski, and Dechmann, 2014; Vandenabeele et al., 2012). The satellite tag uses Beidou technology that is compatible with GPS and GLONASS satellite signals and supplemented with a Satellite-Based Augmentation System position, with a maximum positioning accuracy of $1 \mathrm{~m}$. The satellite tag used in this study has three communication methods: Global System for Mobile Communications, satellite, and very high frequency.

Once tagged, individuals were observed for a period of time, then released after confirming that their activity was normal and they were in good condition. The tracker communicated and returned data via satellite with a positioning frequency of one record per 3 hours. The data attributes included tracker number, time, longitude, latitude, heading, altitude, temperature, voltage, and positioning accuracy. The positioning accuracy of the satellite tracker refers to the closeness between the spatial position of the tracking object and its true position.

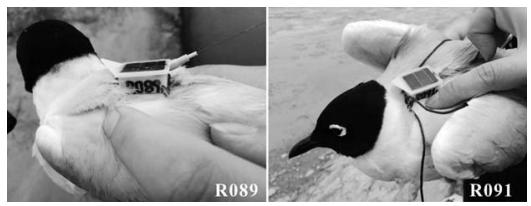

Figure 2. Deploying satellite trackers for the two Saunders's Gulls
The accuracy grade of the used satellite tracker is divided into five levels: A (5 m), B (10 m), C (20 m), D (100 m), and E (2000 $\mathrm{m})$, and the confidence level of the positional accuracy of the tracker is $95 \%$. Considering the positioning precision, data at the $\mathrm{D}$ level and above are regarded as valid data. The two Saunders's Gulls, numbered R089 and R091, were in continuous movement during the study period, and it can be inferred from the activity trajectory that their activity range is keeping with their living habits.

After satellite trackers deployed, the data acquisition was as follows: R089 transmitted valid information from 6 May 2018 to 19 July 2018 and 575 pieces of D level and above data were reserved; R091 transmitted information from 5 May 2018 to 24 October 2018 and 556 pieces of D level and above data were received for subsequent analysis.

\section{Land Use Mapping Through Remote Sensing}

To get the land use data of the YRD, 57 GF-2 images with 4-m spatial resolution from 26 May 2015 to 29 October 2017 and four medium-resolution Landsat- 8 remote sensing images (30 $\mathrm{m}$ resolution) acquired in 2015 and 2018 were collected in the research (Supplementary Tables S1 and S2). All of the images had good quality for land surface objects identification, with cloud coverage less than $10 \%$.

In the study, based on multisource remote sensing data (GF2 and Landsat-8) and field survey, the land use of YRD was obtained by a visual interpretation method and was classified into eight types on the first level and 26 types on the second level (Supplementary Table S3). In all, 402 in situ samples obtained during field surveys, together with 271 sampling points randomly generated by the "Create Random Points" tool in ArcGIS, were used to check the classification validity with the help of Google Earth images. Then, the cartographic accuracy was valued by establishing a confusion matrix using 
the 673 data pairs, and the overall cartographic accuracy reached $92.16 \%$, with Kappa coefficient of 0.91 . The precision of the land use mapping is good enough to support the research of home range identification and habitat disturbance characteristics analysis for Saunders's Gull.

The exploitation of traditional fossil fuels and the development of new energy sources are the main energy utilization methods in the YRD region (Cao et al., 2015). Oil wells and wind turbines are two in particular and the most representative manufactured objects. These were extracted based on GF-2 images and knowledge from in situ investigations. In total, 20,044 polygons of oil wells and 994 points of wind turbines were identified by a manual visual interpretation method in the YRD area. A large number of oil wells and wind turbines were widely distributed in coastal areas, some even in intertidal zone and shallow waters. In addition, considering the accelerating pace of transportation infrastructure construction in recent years and its possible impacts on Saunders's Gull, the spatial data of roads in the YRD was interpreted based on satellite images of GF-2 in 2015 and Landsat-8 in 2018. The roads in the YRD are divided into high-grade roads (including high-speed, national, and provincial roads) and lowgrade roads (e.g., country roads, township roads). As a result, with the help of ArcGIS software, a total of 5575 lines of road were delineated in the YRD through visual interpretation method.

\section{Home Range Identification}

A Brownian bridge is a continuous-time stochastic model of movement (Horne et al., 2007). BBMM considers both the spatial and temporal component of movement, addressing the problem of connections between successive locations (Grueter et al., 2009; Wells et al., 2014). The calculation formula of this model is simplified as follows:

$$
h(z)=\frac{1}{T} \int_{0}^{T} \varphi\left(z ; \mu(t), \sigma^{2}(t)\right) d_{t}
$$

where, $\sigma^{2}(t)=T_{\alpha}(1-\alpha) \sigma_{m}^{2}+(1-\alpha)^{2} \delta_{\alpha}^{2}+\alpha^{2} \delta_{b}^{2}$, and $\alpha=t / T$; $\mathrm{h}(\mathrm{z})$ represents the probability density function of the bird passing two points $a$ and $b$ at the time of $t(t \in[0, T]) ; \sigma_{m}^{2}$ is the Brownian motion variance, a diffusion coefficient associated with the bird's migration speed, which can be calculated by maximum likelihood estimation; and $\delta^{2}$ are errors from GPS. Horne et al. (2007) described in detail the principle and derivation process of the method.

Overall home range size for each Saunders's Gull with tracker numbers R089 and R091 was calculated by BBMM. Using "adehabitatHR" and "adehabitatLT" packages in R 3.6.0, prevailing methods for calculating home range of animal, the home range of Saunders's Gull was determined at different levels, i.e. $95 \%, 80 \%, 65 \%$, and $50 \%$, of the total probability of space use. The BBMM gives the probability density to relocate the animal at a given place. The home range deduced from the BBMM is the minimum area on which the probability to relocate the animal is equal to a specified value. For example, the $95 \%$ home range corresponds to the smallest area on which the probability to relocate the animal is equal to 0.95 . The $95 \%$ and $50 \%$ home ranges were defined as the main and core home range, respectively, in accordance with Seaman et al. (1999),
Hemson et al. (2005), and Laver and Kelly (2008). Then the home range was calculated and visualized in a Geographic Information System (i.e. ArcGIS software).

Because the home range area may vary greatly between different individuals, the overlap area of the home range alone cannot reflect the degree of the overlap for different individuals. In this study, overlap index (OI) was calculated to measure the degree of the overlap between different individuals' core and main home range. The calculation formula of OI is as follows (Atwood and Weeks Harmon, 2003):

$$
\mathrm{OI}=\sqrt{\frac{\text { area }_{\alpha \beta}{ }^{2}}{\text { home range }_{\alpha} * \text { homerange }_{\beta}}}
$$

where, home range $\alpha$ and home range $e_{\beta}$ are the area of individual $\alpha$ and $\beta$, respectively, and rrea $_{\alpha \beta}$ represents overlap area of the home range of the individual $\alpha$ and $\beta$. The value of OI ranges from 0 to 1 , where 0 means no overlap and 1 represents complete overlap. The overlap area is calculated with ArcGIS 10.2 .

\section{Methods for Habitat Disturbance Analysis}

Kernel density estimation (KDE) is a nonparametric method using local information defined by kernels to estimate densities of specified features at given locations (Shi, 2010). In this research, in order to explore relationship of the key manufactured objects with the home range selection of the Saunders's Gull, the spatial distribution characteristics of key manufactured objects in the YRD were obtained using the KDE technique. That is to say, the number and density of the wind turbines or oil wells in the unit area around the unit grid were estimated by calculating them in a unit grid.

Buffer zone analysis, an effective means to describe the influence of geographical objects on the surrounding area and solve the spatial proximity problem (Kang and Lin, 2014), was used to explore the impacts of road construction on the home range selection of Saunders's Gull. In this research, 14 buffers were built for the roads, with a width of $0.5 \mathrm{~km}$ and a range of 0 to $7.5 \mathrm{~km}$, for overlap analysis with the positioning data.

\section{RESULTS}

The BBMM was performed on data from R089 and R091 for home range identification. Based on the home range area of Saunders's Gulls, the land use map, and the manufactured objects distribution of the YRD study area, spatial overlay analysis was used to reveal the spatial correlations and conflicts between them.

\section{Home Range Identification}

During the tracking period, the different motion ranges of the two Saunders's Gulls were clearly demonstrated (Figure 3). Comparatively, the Saunders's Gull numbered R089 had a larger activity range. After being released in Kenli District of Dongying city on 5 May 2018, R089 flew following the route of the coast of Bohai Bay through the cities of Binzhou, Cangzhou, and Tianjin, in turn. When it arrived at Nanpu wetland in the city of Tangshan on 31 May 2018, the northernmost tip of its movement, R089 began to move south along the Bohai Bay on 9 June 2018 and then returned to Hekou District of Dongying city after 2 days. Compared with R089, R091 had a narrow 


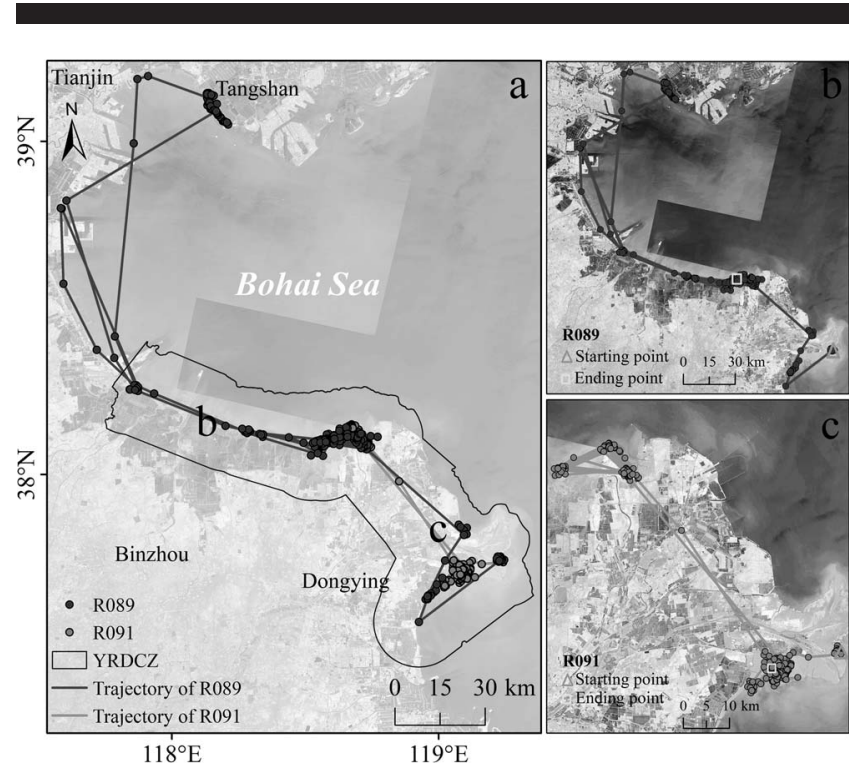

Figure 3. Satellite movement tracks of the Saunders's Gulls along the Bohai coast. (a) The trajectories of R089 and R091 are indicated by green and blue solid lines, respectively. The details of the trajectories of (b) R089 and (c) R091. (Color for this figure is available in the online version of this paper.)

activity territory. The Saunders's Gull moved from Kenli District to the eastern coastal area of Dongying city during the period of 5 May 2018 to 19 May 2018. Then, it flew to the northern inshore area of Hekou District of Dongying city on 20 May 2018, and, finally, R091 came back to the eastern wetland of Kenli District.

Taking into account the definition of the home range and the feature of the BBMM to automatically eliminate tracking points that are not enough to form the home range, most areas of the movement path with a low density of GPS points were not recognized as the Saunders's Gull home range. The spatial distribution of the different levels of the Saunders's Gull's home range could be explained from Figure 4. In terms of geometry, the extension direction of home range is relatively consistent with that of movement. From the spatial perspective, core home ranges were mainly distributed in the Nanpu wetland of Tangshan and the east and north coastal area of Dongying, which basically corresponds to the YRD National Nature Reserve (YRDNNR) region. From the angle of the home range area, the core home range areas of R089 and R091 were 85.09 $\mathrm{km}^{2}$ and $68.67 \mathrm{~km}^{2}$, respectively, with an OI of 0.12 , and, as a result, the total area of core home range was $144.67 \mathrm{~km}^{2}$; whereas the main home range areas were $1014.54 \mathrm{~km}^{2}$ and $1280.22 \mathrm{~km}^{2}$, respectively, and the OI was 0.42 , with a total $1868.87 \mathrm{~km}^{2}$ area for the main home range.

\section{Land Use in the Home Range}

Spatial analysis results (Figure 5) showed that within the entire study area, the top five land use types with the largest proportions were mariculture $(24.42 \%)$, farmland $(14.83 \%)$, salt pan $(11.64 \%)$, industrial-mining land $(7.94 \%)$, and shrubgrass saline-alkali land (6.61\%). The proportion of mariculture area was the largest in the main home range, reaching $23.09 \%$,
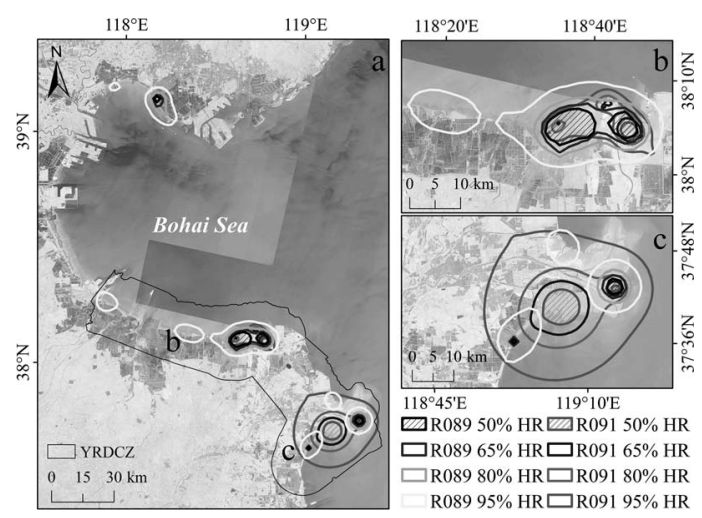

Figure 4. Spatial distribution in different levels of the two Saunders's Gulls' home range using the Brownian bridge movement model (BBMM). (a) The overall spatial distribution of the shorebird's home range. (b) and (c) are part enlarged views for their home range. The contour lines in different colors represent the boundaries of different levels of BBMM home ranges. For example, the red and blue outlines represent the $50 \%$ home range boundaries (core home range) of the gulls, respectively. In addition, the 15$\mathrm{km}$ buffer zone of the birds' migration path in the YRD is indicated by an irregular black shape. (Color for this figure is available in the online version of this paper.)

followed by beach saline-alkali land (11.55\%), shrub-grass saline-alkali land $(9.77 \%)$, suaeda saline-alkali land $(9.18 \%)$, and farmland $(8.49 \%)$.

By comparing the proportions of land use types in YRDCZ and the main home range, it was found that the Saunders's Gull preferred land use types rich in food, water, and shelter, such as mariculture and saline-alkali land. Nevertheless, it is worth noting that there is still a certain proportion of industrial-mining land $(5.80 \%)$ and transportation land

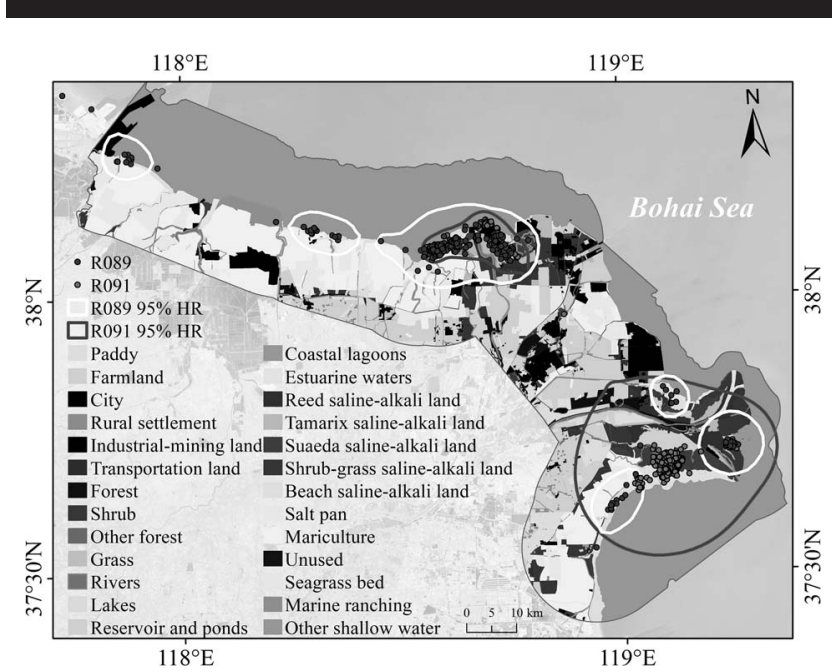

Figure 5. Land use distribution in the main home range of Saunders's Gulls calculated using the BBMM method. In addition to natural habitats (e.g., Suaeda saline-alkali land), a large number of artificial land uses, such as salt pan, industrial-mining land, and mariculture, was also widely located in the main home range. (Color for this figure is available in the online version of this paper.) 


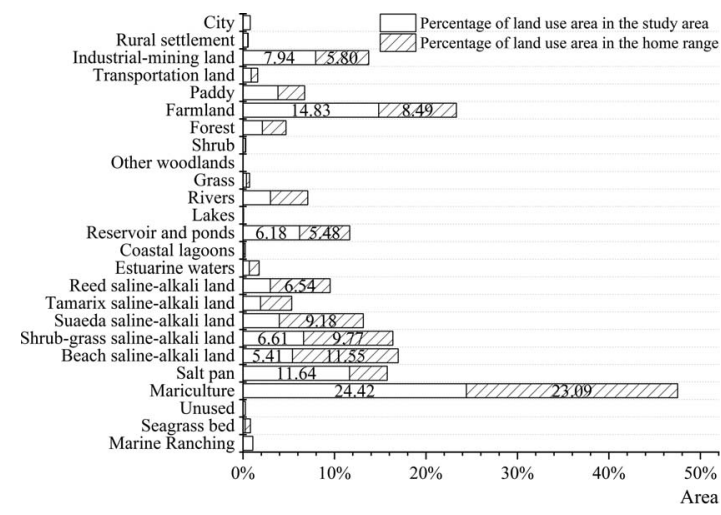

Figure 6. Land use in YRDCZ and the main home range of Saunders's Gulls. The $\mathrm{Y}$-axis stands for various types of the land use, and the $\mathrm{X}$-axis represents the percentage of them. The white bar represents the percentage of land use area within YRDCZ, whereas the shaded bar is that within the home range.

$(0.71 \%)$ in the shorebird's home range (Figure 6), suggesting that industrial mining and road use had a disturbing influence on its home range selection.

\section{Habitat Disturbance from Manufactured Objects}

It can be seen in Figure 7 that a large number of oil wells and wind turbines are distributed in YRDCZ, and there is a spatial consistency between the Saunders's Gull's home range and the YRDNNR. Spatial overlay analysis was performed to explore the influence of manufactured objects on the Saunders's Gull's habitat selection.

The number and density of oil wells and wind turbines in different regions are shown in Tables 1 and 2.

The density of oil wells in YRDCZ reached $1.47 / \mathrm{km}^{2}$, and the density of wind turbines reached $0.47 / \mathrm{km}^{2}$. Even in the YRDNNR, there are 1252 oil wells and 33 wind turbines, with a density of $0.67 / \mathrm{km}^{2}$ and $0.09 / \mathrm{km}^{2}$, respectively. The YRDNNR
Table 1. The number and density of oil wells and wind turbines in Yellow River Delta coastal zone (YRDCZ) and YRD National Nature Reserve (YRDNNR).

\begin{tabular}{lccc}
\hline \hline \multirow{1}{*}{\multicolumn{1}{c}{$\begin{array}{c}\text { Statistics of Area, Number, } \\
\text { and Density }\end{array}$}} & & \multicolumn{2}{c}{ YRDNNR } \\
\cline { 3 - 4 } & YRDCZ & Core Zone & Total \\
\hline Area $\left(\mathrm{km}^{2}\right)$ & 5846.70 & 429.34 & 1529.87 \\
Number of oil wells & 8621 & 27 & 1418 \\
Density of oil well (units $\left./ \mathrm{km}^{2}\right)$ & 1.47 & 0.06 & 0.93 \\
Number of wind turbines & 640 & 0 & 33 \\
Density of wind turbine (units $\left./ \mathrm{km}^{2}\right)$ & 0.11 & 0 & 0.02 \\
\hline
\end{tabular}

is an important habitat for the Saunders's Gull, but as many as 27 oil wells are distributed in the core zone of the nature reserve, which undoubtedly caused great interference in the habitat selection of the shorebird.

There were 19 oil wells $\left(0.22 / \mathrm{km}^{2}\right)$ and 40 wind turbines $\left(0.47 / \mathrm{km}^{2}\right)$ in the core home range of $\mathrm{R} 089$, and 10 oil wells $\left(0.15 / \mathrm{km}^{2}\right)$ and no wind turbines in R091's core home range. It is shown that 822 oil wells $\left(0.81 / \mathrm{km}^{2}\right)$ and 167 wind turbines $\left(0.16 / \mathrm{km}^{2}\right)$ were distributed in the main home range of $\mathrm{R} 089$, whereas 765 oil wells $\left(0.60 / \mathrm{km}^{2}\right)$ and 54 wind turbines $(0.04 /$ $\mathrm{km}^{2}$ ) were in R091's main home range. Statistics showed 1252 oil wells and 167 wind turbines in the main home range of the two birds, whereas 21 oil wells and 40 wind turbines were in the core home range, respectively, which indicated that the birds had a tendency to avoid the two artificial structures in home range selection. Furthermore, the distribution density of oil wells and wind turbines in the different home range of R091 is less than that of R089, suggesting that R091 showed a more significant avoidance behavior for the two manufactured objects than R089.

About $65.25 \%$ and $98.77 \%$ of the core home range of R089 and R091 were located within the nature reserve, indicating the nature reserve, as the main area for the shorebirds' activity, plays an important role in protection of the Saunders's Gull. Although there are manufactured disturbances in the nature

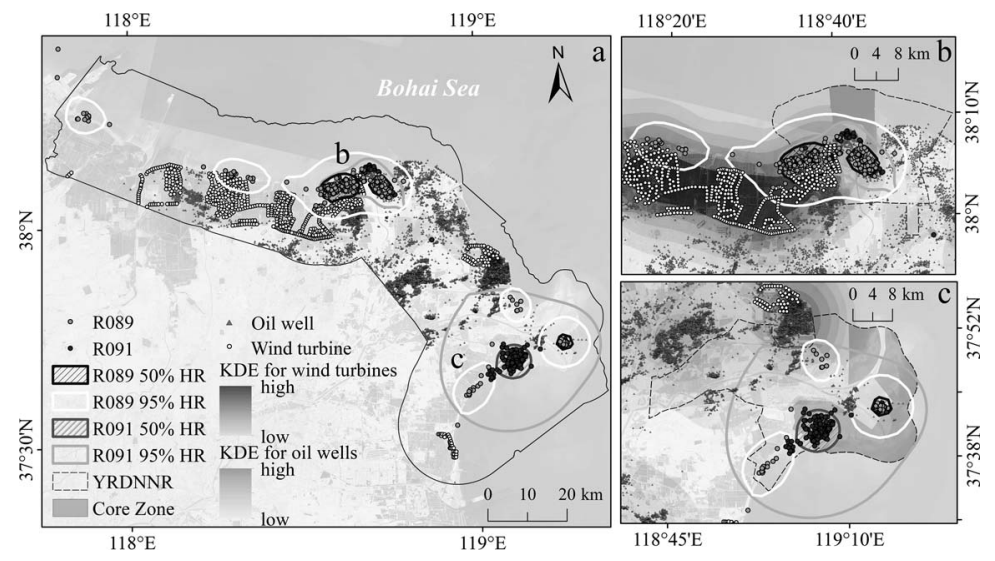

Figure 7. Overlapping characteristics between the two artificial objects and Saunders's Gulls' home range. (a) The spatial distribution of oil wells and wind turbines, location of the gulls' satellite positioning points, and the BBMM home range at different levels. (b, c) The spatial overlay of oil wells, wind turbines, home range, and the YRDNNR. The black dotted line is the boundary of the YRDNNR, and the core zone of YRDNNR is purple-filled. It can be seen that oil wells and wind turbines are widely distributed in the main home range of the gull and the nature reserve. (Color for this figure is available in the online version of this paper.) 
Table 2. The number and density of oil wells and wind turbines in different home range. The overlapping areas of the home ranges were merged, and the corresponding number of oil wells and wind turbines were also merged.

\begin{tabular}{|c|c|c|c|c|c|c|}
\hline \multirow[b]{2}{*}{ Statistics of Area, Number, and Density } & \multicolumn{3}{|c|}{ Core $(50 \%)$ Home Range } & \multicolumn{3}{|c|}{ Main (95\%) Home Range } \\
\hline & R089 & R091 & Total & R089 & R091 & Total \\
\hline Home range area $\left(\mathrm{km}^{2}\right)$ & 85.09 & 68.67 & 144.67 & 1014.54 & 1280.22 & 1868.87 \\
\hline Number of oil wells & 19 & 10 & 21 & 822 & 765 & 1252 \\
\hline Density of oil well (units $/ \mathrm{km}^{2}$ ) & 0.22 & 0.15 & 0.15 & 0.81 & 0.6 & 0.67 \\
\hline Number of wind turbines & 40 & 0 & 40 & 167 & 54 & 167 \\
\hline Density of wind turbine (units $/ \mathrm{km}^{2}$ ) & 0.47 & 0 & 0.28 & 0.16 & 0.04 & 0.09 \\
\hline
\end{tabular}

reserve, the density of oil wells and wind turbines is relatively small compared to the outside of the reserve. By comparing the different density of the manufactured objects in YRDCZ, YRDNNR, and the home range, it can be seen that the density of the two manufactured objects in the nature reserve is smaller than that in YRDCZ. Similarly, the density of oil wells and wind turbines in the core home range is also smaller than that in the main home range. It is concluded that the Saunders's Gull has a clear tendency to avoid oil wells and wind turbines in home range selection.

From overlapping characteristics between the two artificial objects and Saunders's Gulls' home range (Figure 7a), it was found that there is more human interference in the northern home range than in the southern, where there are mainly oil wells distributed. In order to further explore the influence of the distribution of the two particular manufactured objects on the home range selection of the Saunders's Gull, KDE was carried out on the oil well and wind turbine spatial data (Figure $7 \mathrm{~b}, \mathrm{c})$. The results showed that on the whole, the core home range of the Saunders's Gull was not in the central cluster area of the oil well, but was located at the northern edge of the main banded area of the wind turbine. There was an obvious spatial conflict and competition between the Saunders's Gull and the wind turbine.

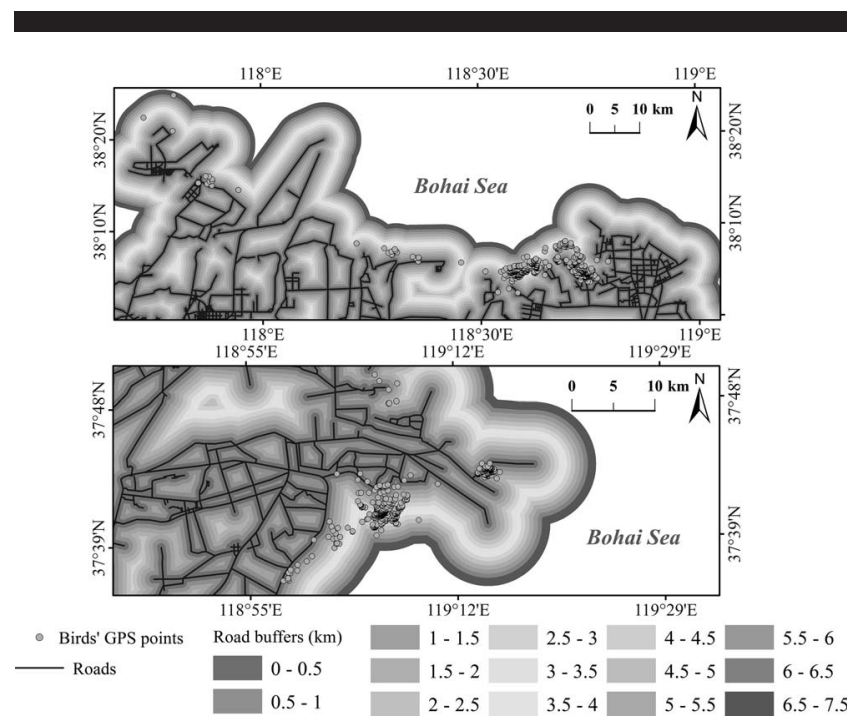

Figure 8. Distribution of the tracking points of Saunders' Gulls at different distances from the road. (Color for this figure is available in the online version of this paper.)

\section{Habitat Disturbance from the Roads}

Distribution of Saunders's Gull's trace points at different distances from the road and during each period of time were gained by the method of overlay analysis for tracking points and 14 buffers of the roads at intervals of $0.5 \mathrm{~km}$. The distribution of tracking points varied in time and space (Figures 8 and 9).

The details were as follows.

There were a number of Saunders's Gull's activity traces in the range of less than $0.5 \mathrm{~km}$ from the road. It was found that these roads were mainly distributed in the YRDNNR, and the activity time of Saunders's Gull was concentrated at 0600 and 1800. That is to say, the average daily activity of Saunders's Gull was characterized by a double peak in the morning and evening; the peak time was the period when people and vehicles were rare on the road, having a weak influence.

In the range of 0.5 to $2.5 \mathrm{~km}$ from the road, the number of the Saunders's Gull's activity traces was small and its activity time was concentrated from 2100 to 0300 of the next day. The average daily activity had a feature of a single peak, indicating that the road significantly made a difference in the home range selection of Saunders's Gull. They had to choose nocturnal activity to avoid the violent disturbance of human activity during the daytime.

In the range of 2.5 to $3.0 \mathrm{~km}$ from the road, there were the largest number of tracking points and the longest stay time for Saunders's Gull. It is worth noting that activity time was concentrated from 0900 to 1200 , with a single peak in average daily activity. Through activity in the daytime, the Saunders's Gull had the largest trace points, suggesting that the road had the least impact on the home range of Saunders's Gull in this range.

There were seldom trace points in the area of $3 \mathrm{~km}$ away from the road and beyond, and the activity time of the Saunders's Gull was concentrated from 1200 to 1500 . This area was far from the main home range of the Saunders's Gull, and the impact of the road rarely existed. In general, the activity frequency of the shorebird during the daytime (0600-1800) was higher than that at nighttime, and 0600 was the peak period of activity, whereas 0000 is the least period of activity. Meanwhile, there were more activities in the morning (0600-1200) than in the afternoon (1200-1800), and the shorebird had the least activity at the period of 1500 in the daytime.

\section{DISCUSSION}

Understanding the ecological requirements of wildlife is an important foundation for effective protection, especially if the number of wildlife is declining due to changes in its primary 


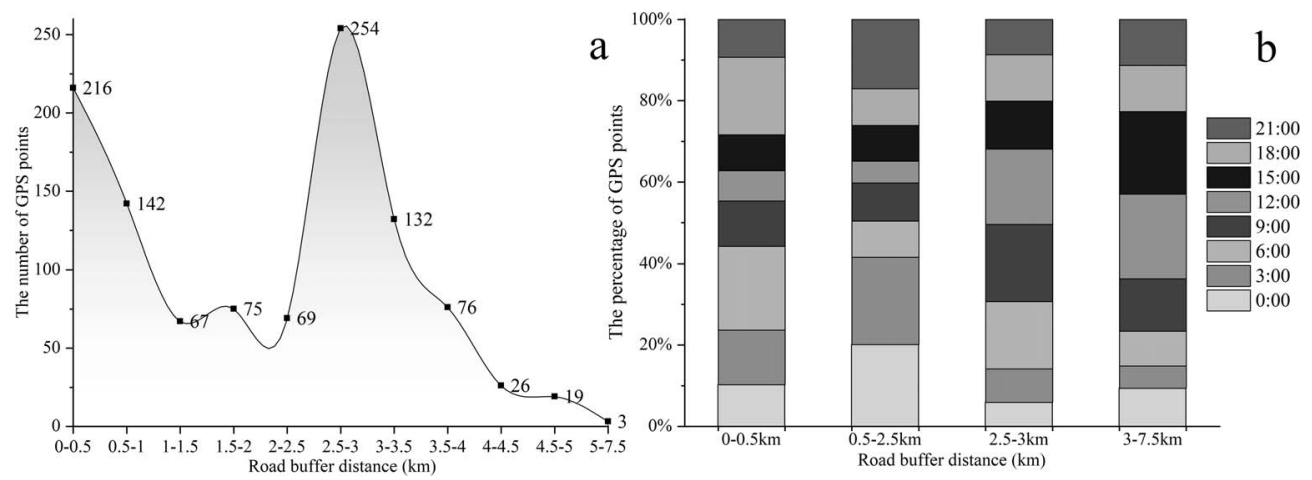

Figure 9. (a) Amount of tracking points at different distances from the road. The number of tracking points has two peaks in the range of 0 to $0.5 \mathrm{~km}$ and 2.5 to 3 $\mathrm{km}$. (b) Proportion of the number of trajectory points at different moments. The number of GPS points varies at different time periods. For example, in the range of 0 to $0.5 \mathrm{~km}$, there are a large number of tracking points at 0600 and 1800 , indicating the gulls avoided the time period of human activities. (Color for this figure is available in the online version of this paper.)

habitats (Seifert, Tegetmeyer, and Ornes, 2018). Taking the Saunders's Gull in the coastal wetland of the YRD as an example, the study identified its home range using one prevailing method: BBMM based on the satellite tracker data.

\section{Home Range Identification and Habitat Selection of the Saunders's Gull}

Previous studies have shown that the widely used BBMM method can achieve better results than the earlier MCP method (Horne et al., 2007; Knüsel et al., 2019; Laver and Kelly, 2008; Powell, 2000). This has also been further confirmed in the research. Using MCPs, the shape of the home range is constrained to be a convex polygon likely including areas that are seldom visited or not visited at all (Harris et al., 1990) and consequently may overestimate the true home range area (Figure 10). Fully considering the nonindependence of the tracking point data and the moving speed of the animal (Pagès et al., 2013), the BBMM introduces the factor of time into the calculation process (Harris et al., 1990), resulting in a sound calculation result (Figure 4). Seldom affected by extreme

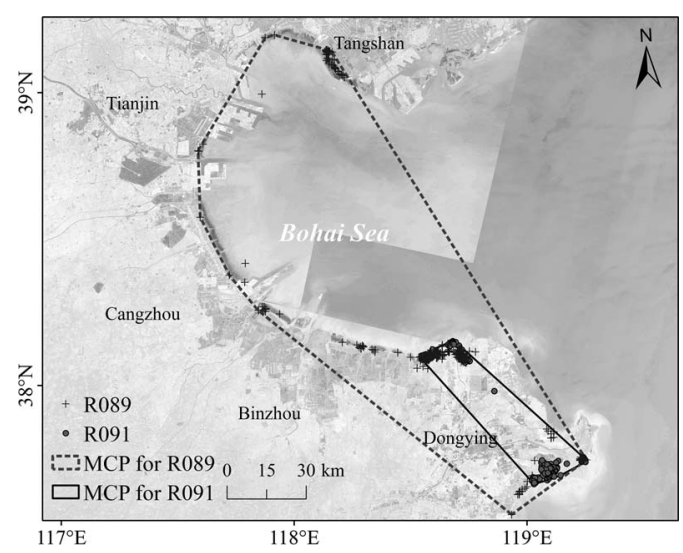

Figure 10. Spatial distribution of the two Saunders's Gulls' home range using the method of minimum convex polygons (MCPs). points, the method integrates time information about the wildlife's location into home range identification to accurately describe the utilization characteristics of the animal within the home range, making the results more ecological.

The position of a species along the movement behavior continuum can be considered as a manifestation of behavioral responses to fluctuating environmental conditions (McEvoy, Hall, and McDonald, 2019). So, home range identification and habitat selection analysis can reflect the habitat environment of a species to a certain extent. Based on data availability, the research focused on the impact of human disturbance on bird habitat selection. The results showed that land use, key manufactured objects, and roads made a significant difference to the Saunders's Gull habitat choice.

The analysis of land use types within the home range indicated that the Saunders's Gull preferred mariculture and saline-alkali land, where there were fewer human activities and which were rich in available food. This has been confirmed by Jiang et al. (2010), who utilized satellite images combined with ground truthing to classify land use and land cover of areas used by Saunders's Gull. It can be explained that shrubgrass saline-alkali land could provide suitable reproduction habitat and mariculture could supply fish and benthic organisms, which was consistent with the living habits of the Saunders's Gull. Also, Figure 6 suggested that resource extraction and road use were the prime human activities in the main home range of the Saunders's Gull. Considering the home range included quite a lot of artificial area, it can be concluded that human activities had already made an impact on the habitat of the Saunders's Gull (Figure 11).

The YRD is an important region of petroleum production in China with a wide distribution of oil wells (Wang et al., 2008). Meanwhile, the YRD region borders the Bohai Sea and has the advantage of wind energy without barriers (Sui et al., 2015). So, oil and wind energy have been developed to meet growing energy consumption. In recently captured remote sensing images, oil wells and wind turbines in YRDCZ were extracted, and many of them were distributed in the YRDNNR coastal areas where the shorebird inhabited. In this research, the 

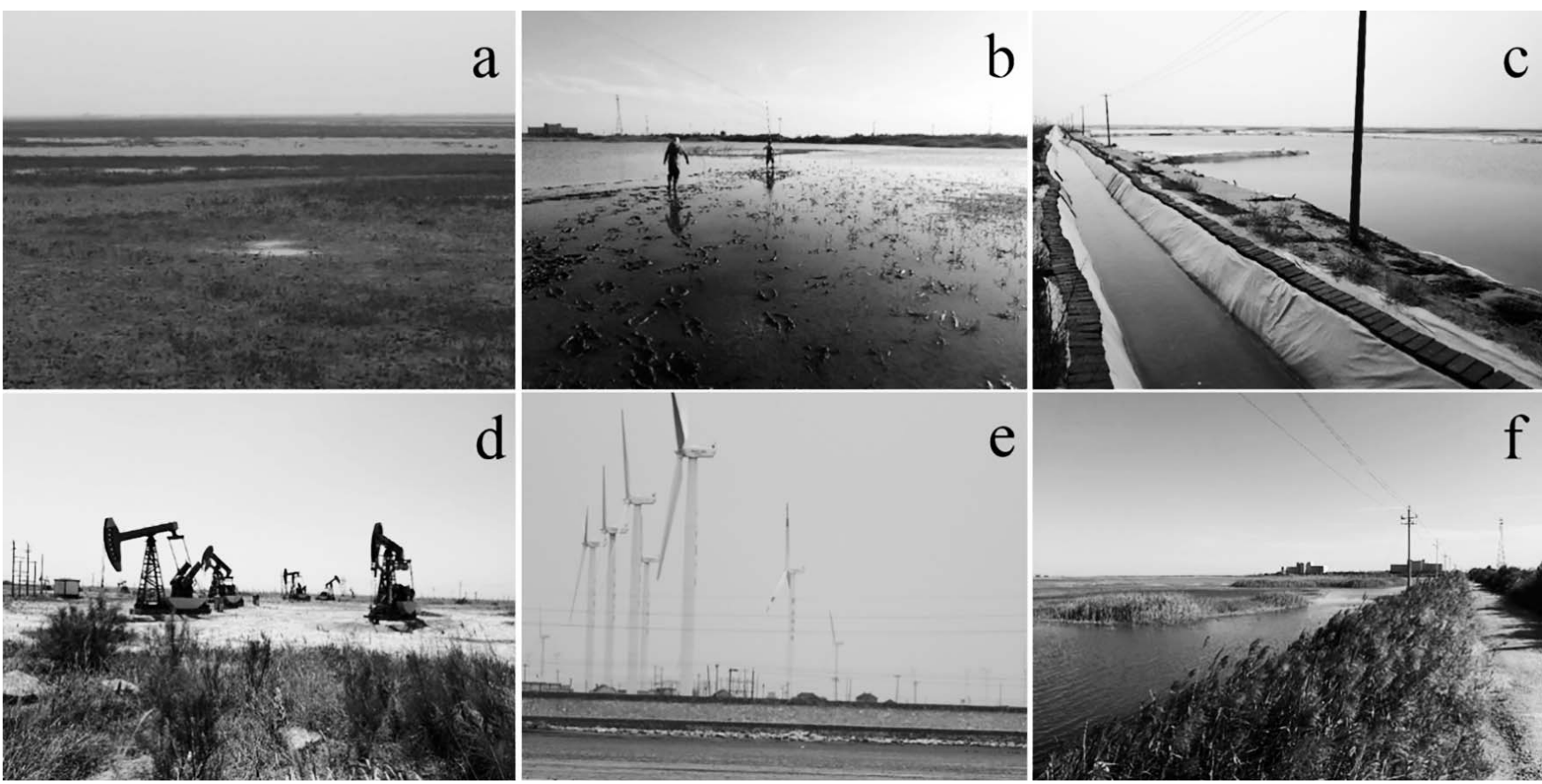

Figure 11. Some natural and manufactured landscapes in the YRD. (a) Suaeda saline-alkali land, (b) beach saline-alkali land, (c) salt pan, (d) oil wells, (e) wind turbines, and (f) roads.

results of spatial analysis showed that the Saunders's Gull tended to avoid oil wells and wind turbines (Tables 1 and 2) and $\mathrm{KDE}$ further found that its home range was more significantly affected by the wind turbine than the oil well (Figure 7). Combined with the long-term field investigation data accumulated in the YRD, the two Saunders's Gull's satellite tracker data available in this research explain to a great extent that oil wells and wind turbines have greatly influenced the habitat selection of the shorebird.

In respect to disturbance from the roads, statistical results displayed that the threat of road construction to habitats of the Saunders's Gull was extremely significant (Figure 8). The number of tracking points varied with the distance from the road or at different times. There was the fewest satellite tracking data in the range of 0.5 to $2.5 \mathrm{~km}$ from the road and the activity of the bird was concentrated in late night (Figure 9) in order to avoid human effect. As one of the most important infrastructures, road construction takes precedence over the other human activities in general. Road construction, which caused the fragmentation of the wetland ecosystem (Figure 11), has becoming one of the key factors affecting the landscape of the YRD. This concurs with the finding of Ito et al. (2018), who showed that new road construction posed a serious threat to wildlife habitat.

\section{Significance of the Saunders's Gull and Implication for Shorebird Habitat Management}

As one of the vulnerable birds in the world, the Saunders's Gull is highly representative of bird biodiversity conservation and has become an important indicator species to measure the quality of ecological environment in the coastal wetlands of the
YRD. Its nest is usually a simple scrape in the ground. It is a poor swimmer, having only partially webbed feet, and usually stays on land, moving up the beach in front of the rising tide (BirdLife International, 2018). So, the quality of its habitat in coastal wetlands is crucial to the survival of this species. During the breeding season, it is mainly dependent on saltmarshes dominated by Seepweed, but many are being drained to make way for aquaculture (Bai et al., 2015; Jiang et $a l ., 2010)$. The main threats it faces are to the degradation of its habitat, most of which are related to human activity for the purpose of harvesting natural resources. Therefore, understanding the home range of the shorebird in the main breeding areas and analyzing the threat factors it faces are of great practical significance for the protection of this species.

In this research using satellite tracking data and mediumand high-resolution remote sensing images, a quantitative analysis of home range selection of the species and its habitat disturbance factors was carried out with spatial statistics methods, which reflected the quality of its habitat to a certain extent. This can provide a decision-making reference for the conservation of coastal wetland and bird habitat in the YRD and other regions in the world. Comprehensive research of wildlife habitat based on various techniques and methods can visually mirror evolution rule of the ecological environment (Barbosa et al., 2020; Li et al., 2019; Mwasi and Acker, 2015). Thus, more and longer period observation is suggested in order to delineate accurate or possible core areas and to have some insight into the species' activity status in the future.

To protect new wetland ecosystems and endangered birds, the YRDNNR was established in 1992 and was on the List of 
Wetlands of International Importance in 2013. Historically, only a few breeding pairs of Saunders's Gull were observed in the YRD in 1998. Since the reserve authority launched the wetland restoration project in Dawenliu (in 2007) and Yiqianer (in 2012) station area, the habitat environment has been greatly improved in the YRDNNR, attracting more shorebirds coming to perch and breed. The YRD population of the Saunders's Gull has shown remarkable growth from 232 individuals in 2012 to 3372 in 2014 (Zhang et al., 2017). In this research, the results of home range identification suggested that core home ranges of the Saunders's Gull were mainly distributed in the core zones of YRDNNR (Figure 7). This fully reflects the importance of the nature reserve in maintaining the balance of wetland ecosystems and protecting vulnerable birds. This is most likely because human activities become increasingly more severe outside the nature reserve and, therefore, it is not suitable for the Saunders's Gull to inhabit. At the same time, Saunders's Gulls had a relatively small activity range outside the nature reserve. It can be speculated that there existed a protection gap for the shorebird in the YRD. Although coastal wetland ecosystems are efficient in resource utilization and energy flux, they are also very fragile and easily disturbed by human activities (Schmitz, 2012). Seifert, Tegetmeyer, and Ornes (2018) showed that intrusions can lead to evasive movements, forcing the birds to abandon former and establish new home ranges. Land reclamation, resource exploitation, agriculture, and aquaculture have rapidly changed the natural habitats in the YRD (Sui et al., 2015), resulting in severe fragmentation of bird habitats in coastal wetlands. So, the dynamic monitoring of the Saunders's Gull's home range and habitat disturbance is of great significance to the biodiversity conservation and harmonious development of the human-environment relationship in the YRD.

With the continuous advancement of China's ecological civilization, ecological environment restoration of the wetlands and biodiversity protection have become two major ecological issues in the YRD. It is recommended to promote sustainable and healthy development of human-land and human-sea relationships in the YRD by rationally and smartly planning energy exploitation, restricting human activities, raising people's awareness of ecological environment and biodiversity protection, strengthening infrastructure construction such as bird rescue and monitoring stations, and intensifying basic research on vulnerable and endangered wild animals.

\section{Advantages and Limitations of the Satellite Tracking for the Saunders's Gull}

Many decisions on the conservation and management of the shorebird are largely informed by knowledge gathered from studies that relied on traditional on-site observation or bird banding (Jiang et al., 2010). However, it is not easy for researchers to conduct an extensive survey for all kinds of Saunders's Gull habitats or to approach some inaccessible habitats such as tidal marshes with a large area of soft quagmire. Fortunately, recent advances in satellite tracking technology solved the problem without affecting individuals' performance and fitness (Burnside et al., 2019). Many researchers take advantage of satellite tracker information to explore the migration status or the habitat environment of birds. For example, Sergio et al. (2014) analyzed satellite tracking data from individuals of a raptorial bird species, showing the development of their migratory behavior followed a consistent trajectory, which suggested that the development of remote tracking is opening new opportunities in migration research. Dixon et al. (2017) monitored the winter ranging behavior of Saker Falcons fitted with satellite-received transmitters, finding that the species preferentially occupied areas with rich grassland (cover $>50 \%$ ) on high latitude plateaus with low levels of anthropogenic influence. It is worth noting that the satellite tracking technique enables the mapping of spatial and temporal patterns of occurrence, helping to understand habitat changes combined with the remote sensing images (Chan et al., 2019). But, at the same time, it should be noted that high costs, including much human power and material resources, are required for the entire satellite tracking process (Coxen et al., 2017), especially when hunting the "Vulnerable" Saunders's Gull in the YRD. As far as is known, this is the first time the satellite tag has been applied to the Saunders's Gull for exploring the human-shorebird conflicts in the YRD. Additionally, habitat selection of animal is affected by a large quantity of factors (Seifert, Tegetmeyer, and Ornes, 2018), including natural environment, human threats, and the physical condition of the animal itself. Also, the home range varies because of different sex or age. However, because Saunders's Gull is sexually monomorphic, it is difficult to recognize its sex just by exterior features such as shape, size, and morphology (Lei et al., 2020). Not knowing the sex and life stage of the tagged individuals, which is one shortcoming of the research, may have some limitations in studying the species' habitat selection.

When analyzing the movement tracks of the Saunders's Gull, the seasonal differences in the species' activity were also noticed. Before June, the tagged Saunders's Gulls had a wide range of activities, especially R089, which moved from Dongying, Shandong Province to Tangshan, Hebei Province following the coast of Bohai Bay. Starting from mid-June, the movement areas of the two individuals were relatively fixed, and the activity range was significantly reduced. R089 was mainly concentrated in the coastal zone of Hekou District, corresponding to the north part of YRDNNR, while R091 was mainly active in the inshore area of Kenli District, corresponding to the south part of YRDNNR. In general, the Saunders's Gull hatches in mid-June every year in the YRD (Liu, 2015). The likely reason of seasonal differences in the shorebird activity is that in June the species began to enter the breeding period after choosing their ideal habitats and the need of nesting and breeding reduced their activity range.

In the research, considering the gregariousness of the shorebird, the tracking sample data, though limited, can reflect the species' habitat selection to a certain extent, providing valuable first-hand information for biodiversity and wetland ecology protection.

\section{CONCLUSIONS}

Taking Saunders's Gull as the research object, this study revealed the threats that the shorebird may face in the YRD. Its home range was identified by BBMM based on satellite 
tracking data, and the habitat disturbance features from land use, manufactured objects, and roads were analyzed using spatial analysis techniques. Although the sample is limited, it represents the habitat selection characteristics of this species to some extent. The main home range of the shorebird was located in the northern and eastern coastal areas of Dongying city, the seashore area at the border of Binzhou with Dongying and Cangzhou city, and the Nanpu wetland of Tangshan city. Under the influence of human activities, land use such as mariculture has had a great impact on the habitat of the Saunders's Gull. The Saunders's Gull tended to avoid manufactured objects such as oil wells and wind turbines. In addition, the distribution of tracking points displayed significant spatial and temporal variance with respect to different distance to the road and different time periods. Home range identification and habitat disturbance analysis for Saunders's Gull have certain reference for the future of the wetland ecosystem sustainability and biodiversity protection in the YRD.

\section{ACKNOWLEDGMENTS}

This research was funded by Strategic Priority Research Program of the Chinese Academy of Sciences, grant numbers XDA19060205, XDA23040203; Science and Technology Service Network Initiative (STS) Project of the Chinese Academy of Sciences, grant number KFJ-STS-ZDTP-023; China Postdoctoral Science Foundation, grant number 2019M652487; and National Natural Science Foundation of China, grant numbers 41901133, 41701212.

The authors are grateful to Yongfa Tang and Tengyi Chen for their work in capturing the Saunders's Gull and installing the satellite tracker.

\section{LITERATURE CITED}

Atwood, T.C. and Weeks Harmon P., Jr., 2003. Spatial home-range overlap and temporal interaction in eastern coyotes: The influence of pair types and fragmentation. Canadian Journal of Zoology, 81(9), 1589-1597.

Bai, Q.; Chen, J.; Chen, Z.; Dong, G.; Dong, J.; Dong, W.; Fu, V.W.K.; Han, Y.; Lu, G., and Li, J., 2015. Identification of coastal wetlands of international importance for waterbirds: A review of China Coastal Waterbird Surveys 2005-2013. Avian Research, 6(1), 1212.

Barbosa, P.; Schumaker, N.H.; Brandon, K.R.; Bager, A., and Grilo, C., 2020. Simulating the consequences of roads for wildlife population dynamics. Landscape and Urban Planning, 193, 103672-103672.

Batsaikhan, N.; Buuveibaatar, B.; Chimed, B.; Enkhtuya, O.; Galbrakh, D.; Ganbaatar, O.; Lkhagvasuren, B.; Nandintsetseg, D.; Berger, J., and Calabrese, J.M., 2014. Conserving the world's finest grassland amidst ambitious national development. Conservation Biology, 28(6), 1736-1739.

Bi, X.; Wang, B., and Lu, Q., 2011. Fragmentation effects of oil wells and roads on the Yellow River Delta, North China. Ocean \& Coastal Management, 54(3), 256-264.

BirdLife International, 2018. Saundersilarus saundersi. The IUCN Red List of Threatened Species 2018: e.T22694436A132551327. http://dx.doi.org/10.2305/IUCN.UK.2018-2.RLTS. T22694436A132551327.en

Buchin, K.; Sijben, S.; van Loon, E.E.; Sapir, N.; Mercier, S.; Arseneau, T.J.M., and Willems, E.P., 2015. Deriving movement properties and the effect of the environment from the Brownian bridge movement model in monkeys and birds. Movement Ecology, $3(1), 18-18$.
Burnside, R.J.; Guilherme, J.L.; Collar, N.J., and Dolman, P.M., 2019. Backpack-mounted satellite transmitters do not affect reproductive performance in a migratory bustard. European Journal of Wildlife Research, 65(6), 98-98.

Burt, W.H., 1943. Territoriality and home range concepts as applied to mammals. Journal of Mammalogy, 24(3), 346-346.

Cao, L.; Barter, M.A., and Wang, X., 2008. Saunders's Gull: A new population estimate. Bird Conservation International, 18(4), 301306.

Cao, M.; Xu, H.; Le, Z.; Zhu, M., and Cao, Y., 2015. A multi-scale approach to investigating the red-crowned crane-habitat relationship in the Yellow River Delta Nature Reserve, China: Implications for conservation. PLoS ONE, 10(6), e0129833.

Chan, Y.C.; Tibbitts, T.L.; Lok, T.; Hassell, C.J.; Peng, H.B.; Ma, Z.; Zhang, Z., and Piersma, T., 2019. Filling knowledge gaps in a threatened shorebird flyway through satellite tracking. Journal of Applied Ecology, 56(10), 2305-2315.

Christel, I.; Navarro, J.; del Castillo, M.; Cama, A., and Ferrer, X., 2012. Foraging movements of Audouin's gull (Larus audouinii) in the Ebro Delta, NW Mediterranean: A preliminary satellitetracking study. Estuarine, Coastal and Shelf Science, 96, 257-261.

Coxen, C.L.; Frey, J.K.; Carleton, S.A., and Collins, D.P., 2017. Species distribution models for a migratory bird based on citizen science and satellite tracking data. Global Ecology and Conservation, 11, 298-311.

Dixon, A.; Li, X.H.; Rahman, M.L.; Batbayar, N., and Zhan, X.J., 2017. Characteristics of home range areas used by Saker Falcons (Falco cherrug) wintering on the Qinghai-Tibetan Plateau. Bird Conservation International, 27(4), 525-536.

Dixon, K.R., and Chapman, J.A., 1980. Harmonic mean measure of animal activity areas. Ecology, 61(5), 1040-1044.

Enners, L.; Chagas, A.L.J.; Ismar-Rebitz, S.M.H.; Schwemmer, P., and Garthe, S., 2019. Foraging patterns and diet composition of breeding Pied avocets (Recurvirostra avosetta) in the German Wadden Sea. Estuarine, Coastal and Shelf Science, 229, 106399.

Franzreb, K.E., 2006. Implications of home range estimation in the management of red-cockaded woodpeckers in South Carolina. Forest Ecology and Management, 228(1-3), 274-284.

Gibbes, C.; Southworth, J., and Keys, E., 2009. Wetland conservation: Change and fragmentation in Trinidad's protected areas. Geoforum, 40(1), 91-104.

Grueter, C.C.; Li, D.; Ren, B., and Wei, F., 2009. Choice of analytical method can have dramatic effects on primate home range estimates. Primates, 50(1), 81-84.

Harris, S.; Cresswell, W.J.; Forde, P.G.; Trewhella, W.J.; Woollard, T., and Wray, S., 1990. Home range analysis using radio-tracking data? A review of problems and techniques particularly as applied to the study of mammals. Mammal Review, 20(2-3), 97-123.

Hemson, G.; Johnson, P.; South, A.; Kenward, R.; Ripley, R., and Macdonald, D., 2005. Are kernels the mustard? Data from global positioning system (GPS) collars suggests problems for kernel home-range analyses with least-squares cross-validation. Journal of Animal Ecology, 74(3), 455-463.

Hirons, G., 1988. Wildlife radio tagging: Equipment, field techniques and data analysis. Trends in Ecology and Evolution, 3(2), 56-57.

Horne, J.S.; Garton, E.O.; Krone, S.M., and Lewis, J.S., 2007. Analyzing animal movements using Brownian bridges. Ecology, 88(9), 2354-2363.

Ito, T.Y.; Sakamoto, Y.; Lhagvasuren, B.; Kinugasa, T., and Shinoda, M., 2018. Winter habitat of Mongolian gazelles in areas of southern Mongolia under new railroad construction: An estimation of interannual changes in suitable habitats. Mammalian Biology, 93(1), 13-20.

Jiang, H.X.; Hou, Y.Q.; Chu, G.Z.; Qian, F.W.; Wang, H.; Zhang, G.G., and Zheng, G.M., 2010. Breeding population dynamics and habitat transition of Saunders's Gull Larus saundersi in Yancheng National Nature Reserve, China. Bird Conservation International, 20(1), 13-24.

Kang, X. and Lin, X., 2014. Graph-based divide and conquer method for parallelizing spatial operations on vector data. Remote Sensing, 6(10), 10107-10130. 
Knüsel, M.A.; Lee, D.E.; König, B., and Bond, M.L., 2019. Correlates of home range sizes of giraffes, Giraffa camelopardalis. Animal Behaviour, 149, 143-151.

Laver, P.N. and Kelly, M.J., 2008. A critical review of home range studies. The Journal of Wildlife Management, 72(1), 290-298.

Lei, W.; Liu, C.A.; Shangguan, K.; Zhou, S.; Liao, G., and Gao, D., 2020. An efficient molecular sexing of the globally vulnerable Saunders's Gull (Saundersilarus saundersi). Conservation Genetics Resources, 12, 533-535.

Li, X.; Hou, X.; Song, Y.; Shan, K.; Zhu, S.; Yu, X., and Mo, X., 2019. Assessing changes of habitat quality for shorebirds in stopover sites: A case study in Yellow River Delta, China. Wetlands, 39(1), $67-77$.

Liu, H., 2015. Progagation study of Saunders's Gull at Shandong Yellow River Delta (in Chinese). Shandong Forestry Science and Technology, 45(5), 86-87+103.

Liu, J.; Engel, B.A.; Dai, L.; Wang, Y.; Wu, Y.; Yan, G.; Cong, L.; Zhai, J.; Zhang, Z., and Zhang, M., 2019. Capturing hydrological connectivity structure of wetlands with indices based on graph theory: A case study in Yellow River Delta. Journal of Cleaner Production, 239, 118059.

Lyu, X.; Yu, J.; Zhou, M.; Ma, B.; Wang, G.; Zhan, C.; Han, G.; Guan, B.; Wu, H., and Li, Y., 2015. Changes of soil particle size distribution in tidal flats in the Yellow River Delta. PLoS ONE, 10(3), e0121368.

Mallon, D.P. and Jiang, Z., 2009. Grazers on the plains: Challenges and prospects for large herbivores in Central Asia. Journal of Applied Ecology, 46(3), 516-519.

Mao, D.; Wang, Z.; Li, L.; Song, K., and Jia, M., 2014. Quantitative assessment of human-induced impacts on marshes in Northeast China from 2000 to 2011. Ecological Engineering, 68, 97-104.

McEvoy, J.F.; Hall, G.P., and McDonald, P.G., 2019. Movements of Australian Wood Ducks (Chenonetta jubata) in an agricultural landscape. Emu-Austral Ornithology, 119(2), 147-156.

Mohr, C.O., 1947. Table of equivalent populations of North American small mammals. The American Midland Naturalist, 37(1), 223249.

Munroe, D.K.; Croissant, C., and York, A.M., 2005. Land use policy and landscape fragmentation in an urbanizing region: Assessing the impact of zoning. Applied Geography, 25(2), 121-141.

Mwasi, S.M. and Acker, K., 2015. Assessment of habitat condition in Kilitome and Nailepo wildlife sanctuaries in south-western Kenya. African Journal of Ecology, 53(4), 595-598.

Nad̀o, L.; Lőbbová, D.; Hapl, E.; Celuch, M.; Uhrin, M.; Šara, M., and Kaňuch, P., 2019. Highly selective roosting of the giant noctule bat and its astonishing foraging activity by GPS tracking in a mountain environment. Mammal Research, 64(4), 587-594.

O'Mara, M.T.; Wikelski, M., and Dechmann, D.K.N., 2014. 50 years of bat tracking: Device attachment and future directions. Methods in Ecology and Evolution, 5(4), 311-319.

Pagès, J.F.; Bartumeus, F.; Hereu, B.; López-Sanz, À.; Romero, J., and Alcoverro, T., 2013. Evaluating a key herbivorous fish as a mobile link: A Brownian bridge approach. Marine Ecology Progress Series, 492, 199-210.

Powell, R.A., 2000. Animal home ranges and territories and home range estimators. In: Pearl, M.; Boitani, L., and Fuller, T. (eds.),
Research Techniques in Animal Ecology: Controversies and Consequences, $2^{\text {nd }}$ edition. New York: Columbia University Press, pp. $65-110$

Schmitz, O.J., 2012. Restoration of ailing wetlands. PLoS Biology, 10(1), e1001248.

Seaman, D.E.; Millspaugh, J.J.; Kernohan, B.J.; Brundige, G.C.; Raedeke, K.J., and Gitzen, R.A., 1999. Effects of sample size on kernel home range estimates. The Journal of Wildlife Management, 63(2), 739-747.

Seifert, N.; Tegetmeyer, C., and Ornes, A.S., 2018. Habitat selection, home range and population size of Baillon's Crake Zapornia pusilla in the Senegal Delta, north-west Senegal. Bird Conservation International, 28(1), 38-58.

Sergio, F.; Tanferna, A.; De Stephanis, R.; Jiménez, L.L.; Blas, J.; Tavecchia, G.; Preatoni, D., and Hiraldo, F., 2014. Individual improvements and selective mortality shape lifelong migratory performance. Nature, 515(7527), 410-413.

Shi, X., 2010. Selection of bandwidth type and adjustment side in kernel density estimation over inhomogeneous backgrounds. International Journal of Geographical Information Science, 24(5), 643-660

Siniff, D.B. and Tester, J.R., 1965. Computer analysis of animalmovement data obtained by telemetry. Bioscience, 15(2), 104-108.

Sui, X.; Chen, L.; Chen, A.; Wang, D.; Wang, W.; Ge, H., and Ji, G., 2015. Assessment of temporal and spatial landscape and avifauna changes in the Yellow River wetland natural reserves in 1990 2013, China. Ecological Engineering, 84, 520-531.

Vandenabeele, S.P.; Shepard, E.L.; Grogan, A., and Wilson, R.P., 2012. When three per cent may not be three per cent; deviceequipped seabirds experience variable flight constraints. Marine Biology, 159(1), 1-14.

Van Winkle, W., 1975. Comparison of several probabilistic homerange models. The Journal of Wildlife Management, 39(1), 118123.

Wang, Z.; Gao, D.; Li, F.; Zhao, J.; Xin, Y.; Simkins, S., and XingBao, S., 2008. Petroleum hydrocarbon degradation potential of soil bacteria native to the Yellow River delta. Pedosphere, 18(6), 707716.

Wells, A.G.; Blair, C.C.; Garton, E.O.; Rice, C.G.; Horne, J.S.; Rachlow, J.L., and Wallin, D.O., 2014. The Brownian bridge synoptic model of habitat selection and space use for animals using GPS telemetry data. Ecological Modelling, 273, 242-250.

Yao, X.; Xiao, R.; Ma, Z.; Xie, Y.; Zhang, M., and Yu, F., 2016. Distribution and contamination assessment of heavy metals in soils from tidal flat, oil exploitation zone and restored wetland in the Yellow River Estuary. Wetlands, 36(1), 153-165.

Yoon, J.; Joo, E.; Yoon, H.; Park, H., and Park, S., 2013. Parent recognition in chicks of the ground-nesting, nidifugous Saunders's Gull Saundersilarus saundersi. Acta Ornithologica, 48(2), 245252.

Zhang, Y.; Liu, B.; Dong, L.; Jiang, H.; Wang, X.; Wang, X.; Song, C.; $\mathrm{Li}, \mathrm{X}$., and Li, S., 2017. High genetic diversity and absence of phylogeographic structure in breeding populations of vulnerable Saundersilarus saundersi (Charadrifformes: Laridae) in Bohai Bay, China. Conservation Genetics, 18(2), 495-500. 
Reproduced with permission of copyright owner. Further reproduction prohibited without permission. 